\title{
Naturally Fractured Tight Gas Reservoir Detection Optimization
}

\author{
Quarterly Report
}

October 1 - December 31, 1996

RECEIVED
NOV 101997
OS 11

Work Performed Under Contract No.: DE-AC21-94MC31224

For

U.S. Department of Energy

Office of Fossil Energy

Morgantown Energy Technology Center

P.O. Box 880

Morgantown, West Virginia 26507-0880

By

Blackhawk Geometrics

301 Commercial Road

Suite B

Golden, Colorado 80401

DISTRHBUTION OF THIS DOCUMENT IS UAMTHE 


\section{Disclaimer}

This report was prepared as an account of work sponsored by an agency of the United States Government. Neither the United States Government nor any agency thereof, nor any of their employees, makes any warranty, express or implied, or assumes any legal liability or responsibility for the accuracy, completeness, or usefulness of any information, apparatus, product, or process disclosed, or represents that its use would not infringe privately owned rights. Reference herein to any specific commercial product, process, or service by trade name, trademark, manufacturer, or otherwise does not necessarily constitute or imply its endorsement, recommendation, or favoring by the United States Government or any agency thereof. The views and opinions of authors expressed herein do not necessarily state or reflect those of the United States Government or any agency thereof. 


\section{DISCLAIMER}

Portions of this document may be illegible electronic image products. Images are produced from the best available original document. 
TABLE OF CONTENTS

1.0 MODELING 3

1.1 AVOA Modeling USINg PARAXIAL RAY TRACING

1.2 Converted WAVE WEll Log Modeling

2.0 3-D 3-C PROCESSING 5

2.1 P-P PROCESSING

5

2.2 P-S PROCESSING

3.0 CORRELATION MATRIX 8

4.0 DIPOLE SONIC LOGGING 10

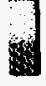

1

1

1

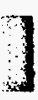

1

1

1

] 


\subsection{MODELING}

\subsection{AVOA Modeling Using Paraxial Ray Tracing}

The goal of this task is to assess the effects of structural complexity and regional anisotropy on a seismic attribute taken to indicate local fracturing and/or gas concentrations, the variation of amplitude with azimuth and offset (AVOA). By using a paraxial ray-tracing code to compute synthetic reflection seismograms, we can construct maps of the AVOA response of the top of the lower Fort Union formation for a complete model reconstruction of the 37 square mile survey. In fact, several dozen models will be run, each with different assumptions about the nature of anisotropy in the Fort Union itself and the overlying Waltman shale. The computed AVOA maps can then be subtracted from the observed AVOA; the remainder will then be a better representation of the amplitude variations that are likely due to fractures and/or gas.

The code was successfully transferred from MIT and installed in October. The following results have been achieved since then:

1. Confirmed that code matched theoretical amplitude response as a function of offset for interface between two isotropic media.

2. Obtained structure-contour map of top of lower Fort Union formation. Regridded at different resolutions. Filtered highest-resolution map using polynomial fits from degree 0 to 6 (see below).

3. Obtained digital observer's notes for 37 square mile survey. Created programs to parse into detailed lists of shot and receiver locations for each shot.

4. Created preprocessor to paraxial ray-tracing code that provides reflector geometry and shot-receiver information appropriate to 37 square mile experiment (Figure 1-1).

5. Created postprocessors that perform common-reflection point gathers and calculate AVOA response.

6. Performed time trials using different fractions of the data set. A working "lowresolution" map can be constructed using $1 / 10$ of the shots and $1 / 10$ of the receivers in about 3 hours of computer time. A "high-resolution" map using the full experiment takes about 100 hours per model. Therefore we have elected to use low-resolution models to test the basic hypotheses and move to selected high-resolution models for later confirmation.

7. Tested AVOA response for increasingly complex representations (polynomial fits) of reflector. Both mean and standard deviation of AVOA in some cases are significantly affected by reflector geometry (Figure 1-2), but the exact relationship has not yet been established. 
Figure 1-1 Rays reflected from Top of Lower Fort Union

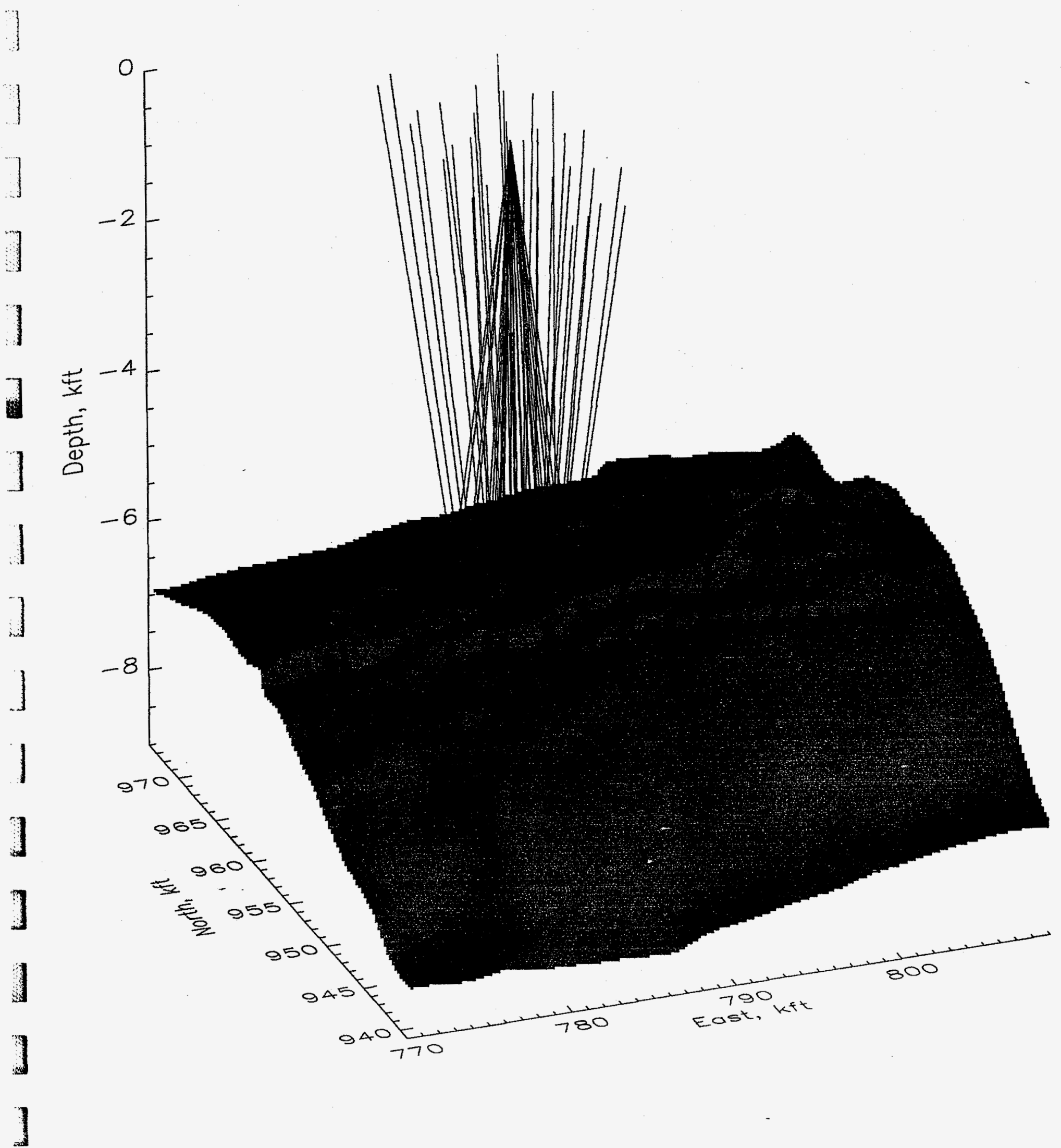




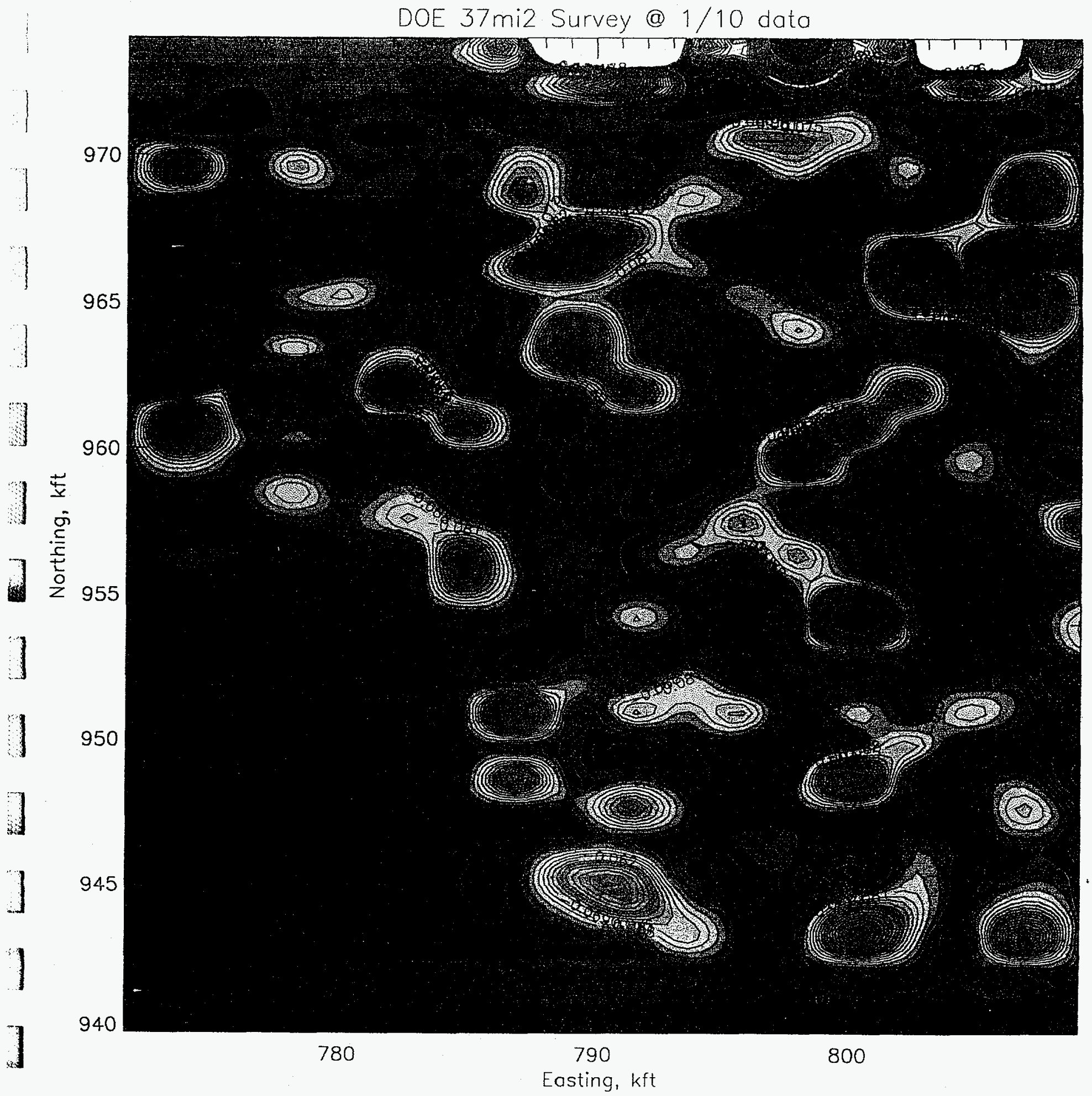

]

Figure 1-2: Apparent normal-incidence reflection coefficients computed by paraxial ray tracing using homogeneous, isotropic layering but actual, deformed interface. Deviations from theory (low = blue, high $=$ red) of a few tens of percent are introduced by finite accuracy of reflection-point repositioning on the interface, illustrating that structure does affect amplitude calculations. 


\subsection{Converted Wave Well Log Modeiing}

Five wells within the boundary of the 3-D, 3-C survey have been modeled. The most significant by-product of this modeling is to provide converted wave synthetic seismograms for comparison to the converted wave 3-D dataset. The locations of the five wells with respect to the 3-D, 3-C survey are shown in Figure 1-3. Comparisons of the converted wave synthetic seismograms to the preliminary stacks from the converted wave 3-D showed excellent agreement.

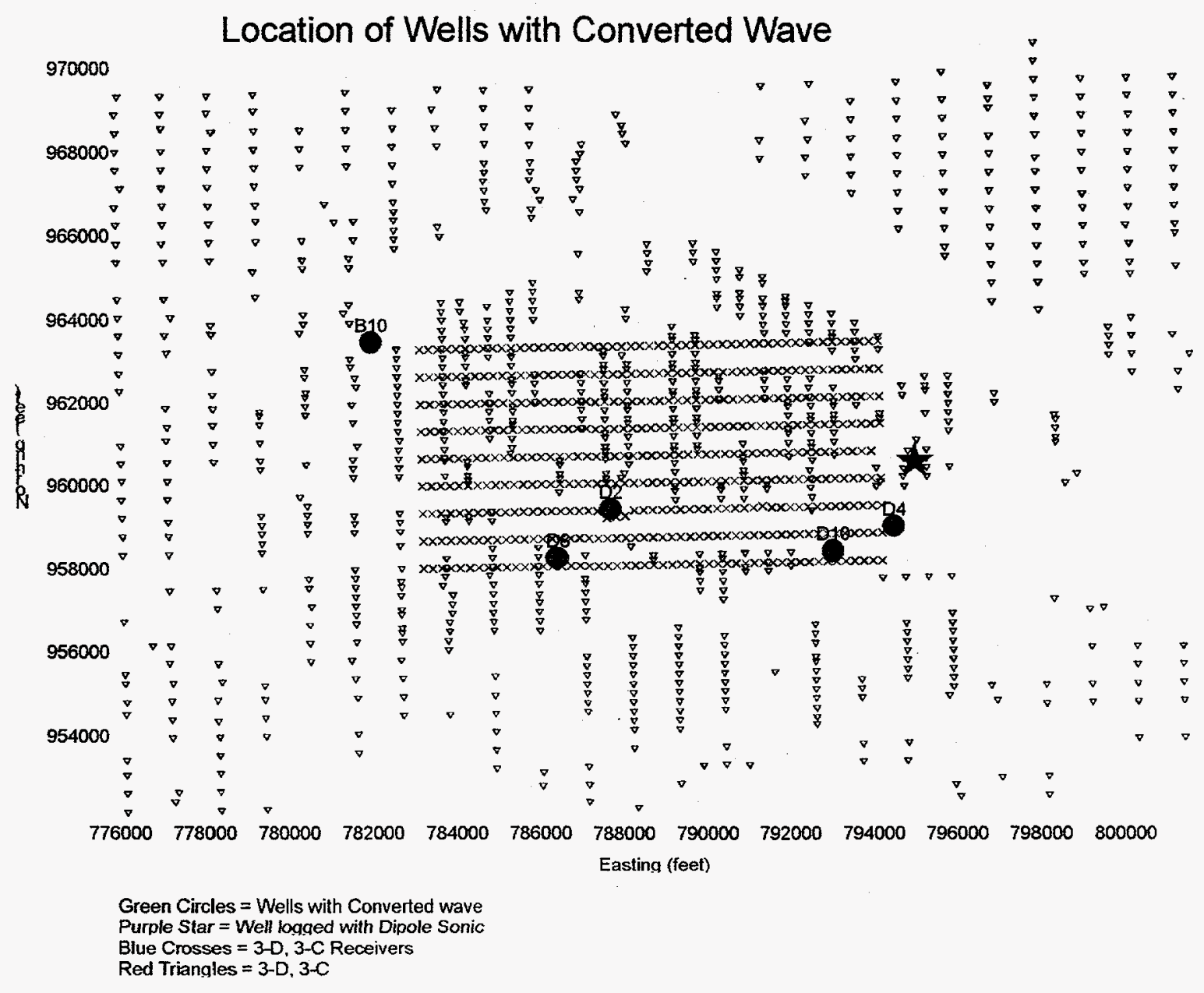

Figure 1-3- 


\subsection{3-D 3-C PROCESSING}

The processing of both the compressional wave $(P-P)$ data and the converted wave (P-S) data is nearly finished. Processing is scheduled to be completed by February, 1997.

\subsection{P-P Processing}

Final migrated stacks of the P-P dataset were delivered to Lynn, Inc., during this quarter, and interpretation has begun.

Fractogram analysis is proceeding at Western Geophysical, with QC being provided by Palantir Exploration Services. Fractogram analysis is a method which attempts to determine fracture orientation and fracture density from azimuthal variations in P-wave data.

The processing flow applied to the P-P data is given below. Processes performed prior to this reporting period are shown with a leading asterisk, while processes applied during this reporting period are shown in boldface type. 


\section{Processing Flow for P-P 3-D Dataset}

\begin{tabular}{|c|c|}
\hline Structural Stack & \\
\hline${ }^{*}$ Geometry Description for $\mathrm{V}, \mathrm{H} 1$ and $\mathrm{H} 2$ Components & \\
\hline "Amplitude Recovery Using $T^{1.5}$ Exponential Gain & \\
\hline "RAAC (Residual Amplitude Analysis/Compensation) & \\
\hline *Surface Consistent Deconvolution & \\
\hline *Refraction Statics & \\
\hline "Velocity Analysis & \\
\hline "MISER Reflection Statics & \\
\hline *Iterations of Steps VI and VII to Convergence & \\
\hline *Dip Moveout Application & \\
\hline${ }^{*}$ DMO Velocity Analysis & \\
\hline "Output data to Fractogram Analysis -.. & Fractogram Analysis \\
\hline Stack & *All azimuths with final statics and current velocities \\
\hline Migrate & $\begin{array}{l}\text { Separate data in } 4 \text { azimuth volumes as follows: } \\
0 \text { deg. }(+l-22.5 \text { deg }) \\
45 \mathrm{deg}(+/-22.5 \mathrm{deg} .) \\
90 \mathrm{deg} .(+/-22.5 \mathrm{deg} .) \\
135 \mathrm{deg} .(+/-22.5 \mathrm{deg} .)\end{array}$ \\
\hline \multirow{11}{*}{-} & $\begin{array}{l}\text { Run DMO monitors at selected locations for velocity } \\
\text { analysis for each volume }\end{array}$ \\
\hline & $\begin{array}{l}\text { Pick DMO velocities for each volume (limit far offsets } \\
\text { as below) }\end{array}$ \\
\hline & $\begin{array}{l}\text { Divide volumes from (2) into near (0 to } 3000 \mathrm{ft} \text { ) and } \\
\text { far ( } 3000 \text { to } \sim 7000 \mathrm{ft} \text {.) offset volumes for a total of } 8 \\
\text { volumes. }(3000 \mathrm{ft} \sim 15 \mathrm{deg} \text {. at } 1.2 \mathrm{sec})\end{array}$ \\
\hline & $\begin{array}{l}\text { Calculate EQ DMO weights for all } 8 \text { volumes } \\
\text { individually }\end{array}$ \\
\hline & $\begin{array}{l}\text { Progressive EQ DMO and Stack for all } 8 \text { volumes } \\
\text { Near offsets may be done at } 110 \mathrm{ft} \text {. by } 220 \mathrm{ft} \text {. cell size to } \\
\text { improve fold }\end{array}$ \\
\hline & $\begin{array}{l}\text { Time Migration of all } 8 \text { volumes (Extended Stolt - single } \\
\text { velocity function) }\end{array}$ \\
\hline & Provide client with 8 volumes for interpretation \\
\hline & $\begin{array}{l}\text { Develop amplitude scalar field from near offset volumes } \\
\text { Calculate amplitude envelope volumes } \\
\text { Spatial and temporal averaging } \\
\text { Interpolation back to } 110 \mathrm{ft} \text { by } 110 \mathrm{ft} \text { cell } \\
\text { Sum } 4 \text { smoothed volumes, output average volume } \\
\text { Divide average envelope volume by individual envelope } \\
\text { volumes } \\
\text { Create ratio volume for each of } 4 \text { volumes }\end{array}$ \\
\hline & $\begin{array}{l}\text { Normalize far offset volumes - multiply by appropriate ratio } \\
\text { volumes }\end{array}$ \\
\hline & Run fractogram analysis with normalized far offset volumes \\
\hline & Provide client $\Phi$ and $B / A$ volumes for interpretation \\
\hline
\end{tabular}




\subsection{P-S Processing}

The P-S datasets were presented at Western Geophysical during meetings in

November and December. The quality of the data, and the correlation of the 3-D, 3-C data to the synthetic seismograms were better than had been expected. The common conversion point (CCP) binning was run using only a single bin per input trace at the last meeting (due to a bug in the CCP code), but a three bin per input trace stack has been promised by Western in January.

The schedule of delivery for final stacks of the converted wave data is February, 1997. The P-S processing flow is outlined below. Processes performed prior to this reporting period are shown with a leading asterisk, while processes applied during this reporting period are shown in boldface type.

\section{Processing Flow for P-S 3-D Dataset}

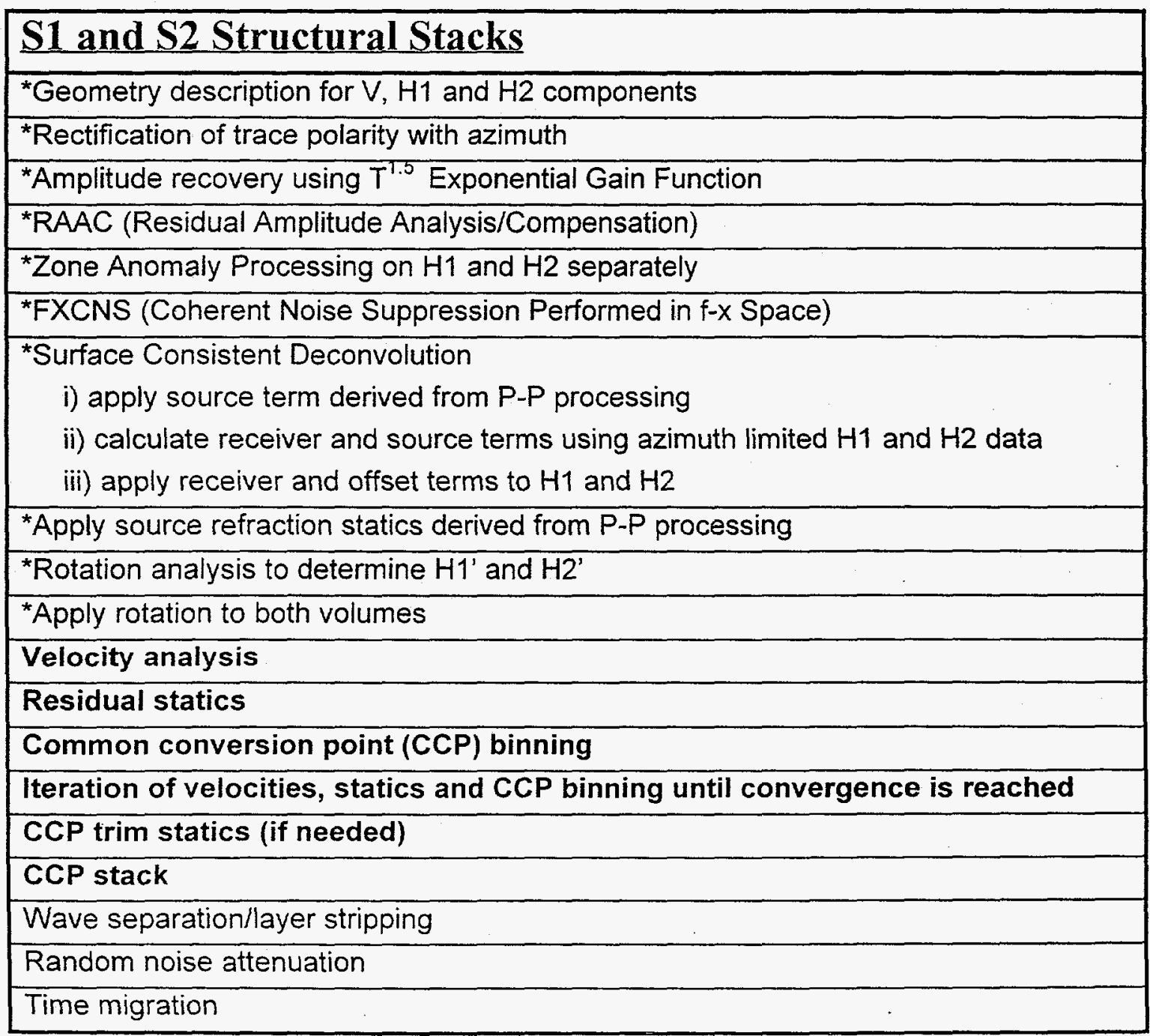




\subsection{CORRELATION MATRIX}

The basis for the correlation matrix is to spatially compare seismic attributes to estimated ultimate recovery (EUR) in wells that lie within the study area. The seismic attributes used in the correlation matrix were discussed in the previous quarterly report.

The field operator has established five categories for EUR. They range from $A$ to $E$, with $A$ representing the most economic category, and $E$ representing non commercial production. To aid interpretation of the seismic attribute map, the EUR classification chart provided by the field operator is given below.

\begin{tabular}{|c|c|}
\hline Category & Range of Estimated Ultimate Recovery \\
\hline A & $>15$ Billion Cubic Feet (BCF) \\
\hline B & $8 \mathrm{BCF}$ to $15 \mathrm{BCF}$ \\
\hline C & $1 \mathrm{BCF}$ to $8 \mathrm{BCF}$ \\
\hline D & 0 BCF to 1 BCF \\
\hline E & Non commercial / Non productive \\
\hline
\end{tabular}

A plan view of the study area is given in Figure 3-1, showing the extent of the 37 square mile 3-D survey, the crest of the anticline, and an outline of the Prospective Seismic Attributes Map given in Figure 3-2. It can be seen that the prospective seismic attributes map lies primarily over the anticline, which should correlate to the area of highest production.

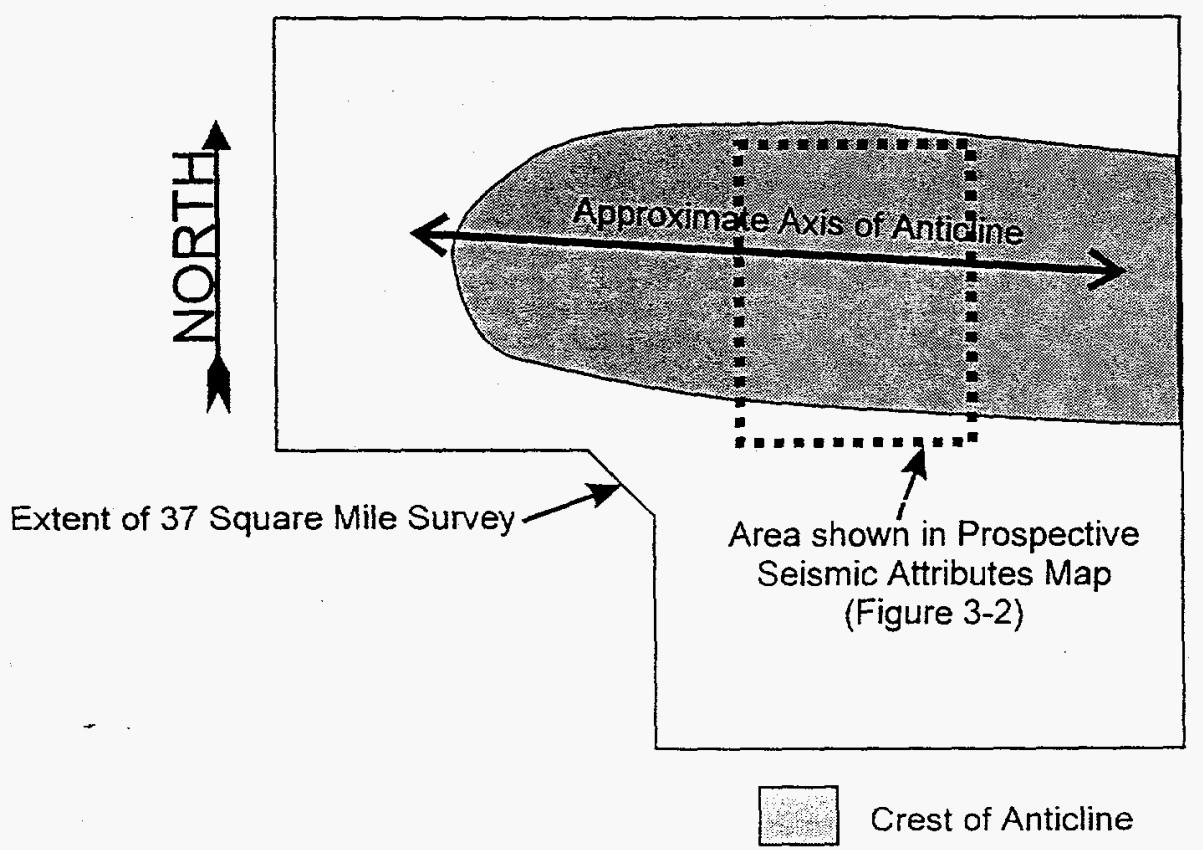

Figure 3-1 Location map of the Prospective Seismic Attributes Map in the Wind River Basin 3-D study Area 


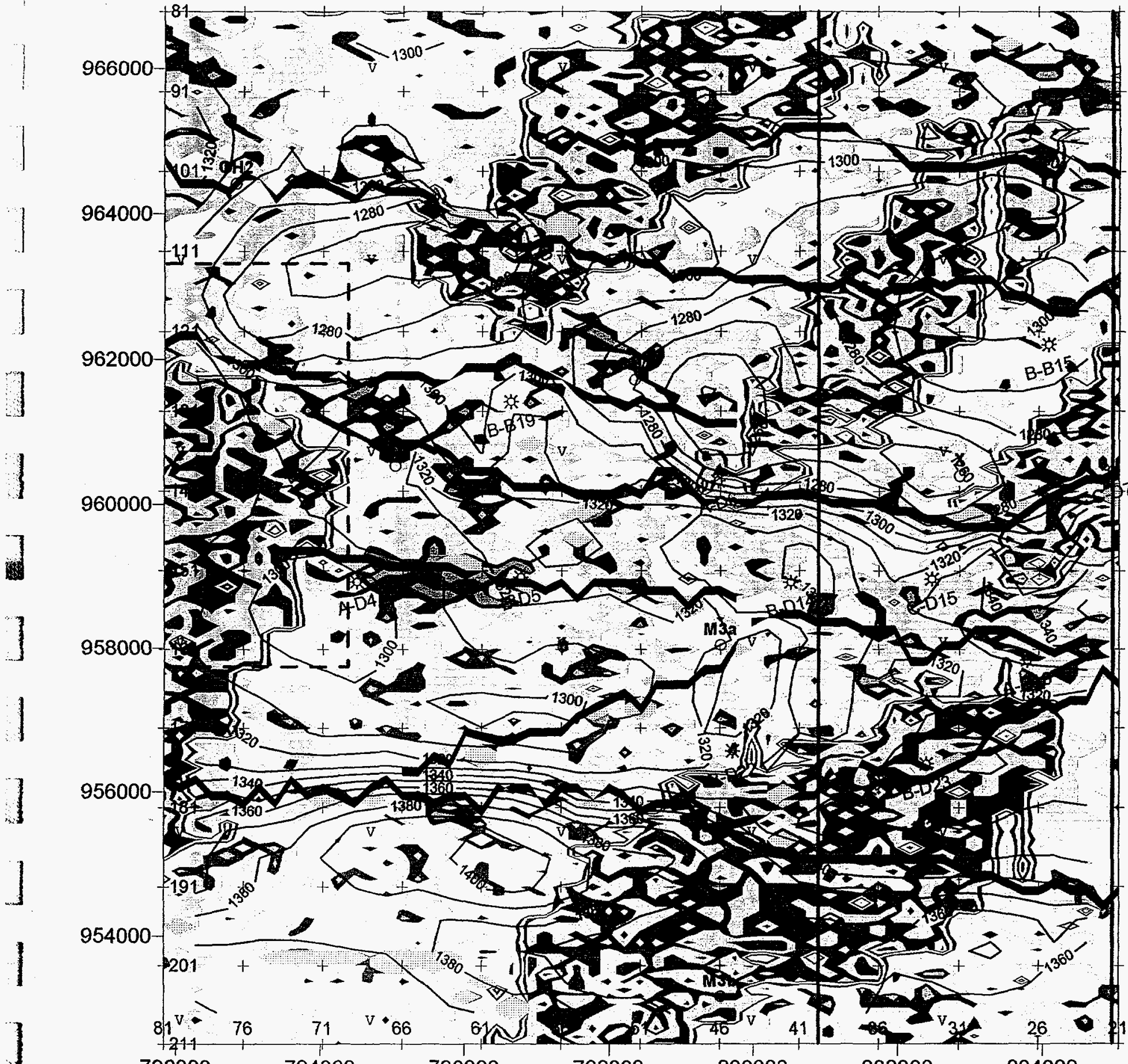

Lynn Incorporated Houston, Texas
D.O.E. Project - Wind River Basin

$792000 \quad 794000 \quad 796000$

798000

800000

802000

804000

$V$ : VELOCITY ANALYSIS LOCATIONS FAULTS AT TOP LFU IN BLACK

-... : : 3-C RECEIVER PATCH

: EW FOLD > 10 \& EW OFFSET > 9K CONTOURS : T/LFU TIME STRUCTURE C.I. 10 MS $\begin{array}{lllllllllll}\text { POSITIVE } & 0 & 1 & 2 & 3 & 4 & 5 & 6 & 7 & 8 & 9\end{array}$ SEISMIC ATTRIBUTES

Data File : C:-_-PROSP2.XLS

Grid File: C:- - PROSP6.GRD

Grid File Time Str. : C:-___EWTIME5.GRD

D:-_ 32-DETDET6.SRF ; 18 OCTOBER - 5 NOVEMBER96
Sample: $220^{\prime} \times 110^{\circ}$ Search radius: $60 \times 60$ Min. Total Data: 1 Max. Empty Sectors : 0 Max. Data / Sector : 1

$0 \mathrm{Ft} \quad 2000 \mathrm{Ft} \quad 4000 \mathrm{Ft} \quad 6000 \mathrm{Ft} \quad 8000 \mathrm{Ft}$


The prospective seismic attribute map in Figure 3-2 was generated using the seismic attributes discussed in the previous report; however, this map is scaled in a manner which weights the interval velocity more than the other attributes.

This approach was suggested by the field operator's Head of Geophysical Research. It was his contention that the interval velocity ratio was the most robust attribute for detecting fractures, and that it should, therefore, carry more weight than the other attributes. After further discussion, it was agreed that the interval velocity attribute should be scaled to a value five times greater than the other four attributes. This unequal weighting scheme is shown in more detail in Tables 3-1 and 3-2 below.

\begin{tabular}{|l|c|}
\hline Attribute & Weight \\
\hline Interval Velocity Ratio & 5 \\
\hline Average Frequency Difference & 1 \\
\hline AVO Gradient Sum & 1 \\
\hline AVO Gradient Difference & 1 \\
\hline Reflection Strength Difference & 1 \\
\hline
\end{tabular}

Table 3-1 Weighting scheme applied to seismic attributes

\begin{tabular}{|c|c|}
\hline Scale & Attribute Interpretation \\
\hline$\overline{0}$ & No prospective attributes \\
\hline 1 & $\begin{array}{l}\text { One prospective attribute with weight of } 1 \\
\text { Velocity attribute non-prospective }\end{array}$ \\
\hline 2 & $\begin{array}{l}\text { Two prospective attributes with weight of } 1 \\
\text { Velocity attribute non-prospective }\end{array}$ \\
\hline 3 & $\begin{array}{l}\text { Three prospective attributes with weight of } 1 \\
\text { Velocity attribute non-prospective }\end{array}$ \\
\hline 4 & $\begin{array}{l}\text { Four prospective attributes with weight of } 1 \\
\text { Velocity attribute non-prospective }\end{array}$ \\
\hline 5 & $\begin{array}{l}\text { No prospective attributes with weight of } 1 \\
\text { Prospective velocity attribute }\end{array}$ \\
\hline 6 & $\begin{array}{l}\text { One prospective attribute with weight of } 1 \\
\text { Prospective velocity attribute }\end{array}$ \\
\hline 7 & $\begin{array}{l}\text { Two prospective attribute with weight of } 1 \\
\text { Prospective velocity attribute }\end{array}$ \\
\hline 8 & $\begin{array}{c}\text { Three prospective attribute with weight of } 1 \\
\text { Prospective velocity attribute }\end{array}$ \\
\hline 9 & All attributes prospective \\
\hline
\end{tabular}

Table 3-2 Ranking scale for prospective seismic attributes shown on Figure 3-2

In Figure 3-2, the warm colors (yellows and reds) correspond to areas where a prospective interval velocity ratio exists, and cool colors (blues and reds) correspond to areas where a no prospective interval velocity ratio exists. Beneath each well symbol in Figure 3-2 is a two part identifier for the well, in the format $X-Y Y$. The $X$ portion of the identifier represents the EUR classification ( $A$ to $E$ ), and the $Y Y$ part of the identifier is the project index number of the well.

Also-shown on the map in Figure 3-2 are the fault locations along the top of the interpreted Lower Fort Union. This figure shows that the highly fractured areas indicated by the seismic attributes do not directly correspond to the fault traces interpreted at the top of the mapped interval. In addition, the general pattern of highly fractured areas inferred from the seismic attributes do not parallel the mapped faults. It is hoped that the paraxial ray trace modeling will lend some insight into these observations. 


\subsection{DIPOLE SONIC LOGGING}

A Dipole Shear sonic Imager (DSI) log was run in a well that lies within the 3-D, 3-C survey area. The location of this well is shown on Figure 1-3 in relation to the 3-D, 3-C survey patch. The DSI log generates both P-and S- waves in the borehole, and measures the P-wave and S-wave velocities, as well as directional information related to the wavefields. This log will be used to calibrate the P-to $S$ - converted wave stacked sections currently being processed at Western Geophysical. From the S-waves generated, both fast (S1) and slow (S2) shear waves are measured. From S1 and S2, the following properties are calculated along the borehole:

- S1 azimuth and azimuth uncertainty

- Time based \% anisotropy

- Slowness based \% anisotropy

- Maximum, minimum, and difference in energy

These quantities will ultimately be compared to the anisotropies and azimuths calculated from the converted wave survey.

From the P- and S- wave velocity fields, Poisson's ratio can be calculated, and several types of synthetic seismograms can be generated. In addition to the converted wave synthetic seismogram, P-and S- wave seismograms will be generated and displayed in depth. The reflected $P$ - and $S$ - wave signatures present on the synthetic seismograms will then be compared.

Figure 4-1 shows a portion of the Dipole sonic log recorded at the site. The window on the far right shows the fast and slow wiggle traces. They are displayed every 10 feet (or 20 sampling points, as this log is sampled at a 0.5 foot interval). The area shaded pink corresponds to the window used for data processing of first breaks.

The log traces in the panel second from the right represent the S1 and S2 time series as calculated from the shear data. The color coded Time \% anisotropy displayed on the right edge of this panel is considered to be the most reliable estimate of anisotropy for the purposes of this project. The slowness based anisotropy is shown on the left edge of this panel.

The center panel shows the calculated azimuth of the fast shear, which theoretically corresponds to the dominant fracture direction. The shaded area surrounding the S1 azimuth trace is the azimuth uncertainty. Note that in areas of high signal strength ( 5490 to $5510 \mathrm{ft}$ ) the $\mathrm{S} 1$ azimuth is very stable, and the uncertainty is low. In areas of low signal strength ( 5420 to $5440 \mathrm{ft}$ ) the $\mathrm{S} 1$ azimuth shows high amplitude, short wavelength variation with a high degree of uncertainty. Because of this relationship, the behavior of the $S 1$ azimuth trace and the azimuth uncertainty are often used to judge the quality of dipole sonic data. 
The panel second from the left shows information concerning the well orientation and the tool orientation in the well, along with the gamma ray trace. The gamma trace is used, along with the shear information, to determine lithology.

The far left panel shows the minimum and maximum energy, and the area between these traces (energy difference) is also an indicator of anisotropy. 


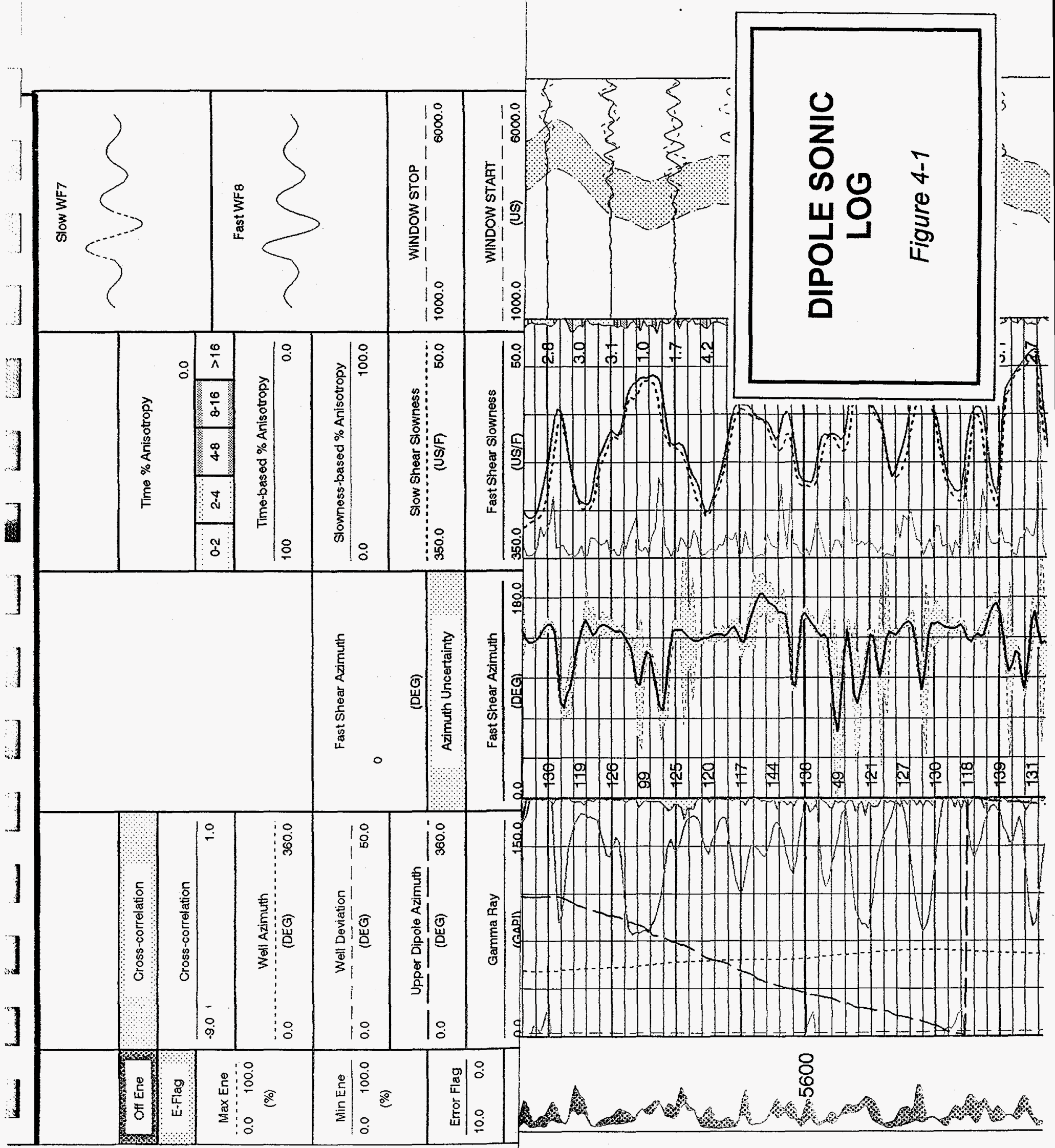




\subsection{TECHNOLOGY TRANSFER}

Three presentations concerning the study were given at the annual convention of the Society of Exploration Geophysicists (SEG) during November, 1996. The titles and authors of the presentations are listed below:

Near surface variability in shear wave velocity anisotropy - C.R. Bates, D. Phillips and E. Lavely, Blackhawk Geometrics, Inc.; and H.B. Lynn, Lynn, Inc.

Naturally fractured gas reservoirs' seismic characterization - H.B. Lynn, K.M.

Simon, Lynn, Inc.; C.R. Bates, Blackhawk Geometrics, Inc.; and R. Van Dok, Western Geophysical

Computation of principal directions of azimuthal anisotropy from P-wave seismic data - S. Mallick, K. L. Craft, L. Meister and R.E. Chambers, Western Geophysical

The abstract for a poster paper submitted to the AAPG for their 1997 annual convention to be held in April, 1996 was accepted. The title is:

Detection of naturally fractured tight gas reservoirs: Case histories from the Uinta and Wind River Basins using 2-D and 3-D seismic data - PHILLIPS, DAVE Blackhawk Geometrics, Golden, CO; HELOISE B. LYNN and MICHELE SIMON, Lynn, Inc., Houston, TX and RICHARD VAN DOK, Western Geophysical, Denver, CO 